\title{
Pancreatitis induced by codeine: a case report with positive rechallenge
}

\author{
P Hastier, F Longo, M Buckley, R M Chichmanian, J P Delmont
}

\begin{abstract}
A woman who developed acute pancreatitis following ingestion of low dose codeine, with positive rechallenge, is described. As this is the first case report of pancreatitis being induced solely by codeine, this side effect must be rare in view of the widespread consumption of this drug.

(Gut 1997; 41: 705-706)
\end{abstract}

Keywords: acute pancreatitis; codeine; sphincter of Oddi spasm

Many drugs have been reported to cause acute pancreatitis. ${ }^{12}$ Codeine related pancreatitis has only previously been reported on one occasion, in association with paracetamol. ${ }^{3}$ We report the first case of codeine induced acute pancreatitis in a woman who had undergone cholecystectomy five months previously.

\section{Case report}

A 26 year old woman was admitted to another hospital in April 1996, complaining of abdominal pain. Cholecystectomy had been performed in 1995. There was no history of alcohol consumption. Two days before admission, she had taken $40 \mathrm{mg}$ of codeine for an upper respiratory tract infection. To her knowledge, she had never taken this drug previously. Three hours after ingestion, she complained of epigastric pain and vomiting. Physical examination was normal. Laboratory tests were as follows: erythrocyte sedimentation rate $19 \mathrm{~mm}$ in the first hour (normal $<10 \mathrm{~mm}$ ); $\mathrm{C}$ reactive protein $5 \mathrm{mg} / \mathrm{dl}$ (normal $<0.5 \mathrm{mg} / \mathrm{dl}$ ); serum amylase $350 \mathrm{IU} / 1$ (normal <110 IU/1); and serum lipase 584 IU/1 (normal <208 IU/1) (fig 1). Liver enzymes, full blood count, and serum creatinine, urea, and electrolytes were normal. After overnight observation, the symptoms resolved. A diagnosis of mild idiopathic pancreatitis was made.

One week later, the patient took $40 \mathrm{mg}$ of codeine for similar respiratory symptoms. Two hours later, she developed epigastric pain which radiated through to her back. She had not taken alcohol or other medication. Physical examination, at our hospital, was normal. Laboratory tests showed serum amylase $167 \mathrm{IU} / 1$, serum lipase $1457 \mathrm{IU} / 1$, and C reactive protein $50 \mathrm{mg} / \mathrm{dl}$. Liver enzymes, bilirubin, calcium, urea, creatinine, cholesterol, and serum triglycerides were all normal. Serological tests for adenovirus, Coxsackie, and Epstein-Barr viruses showed no evidence of recent infection. A computed tomography (CT) scan showed an enlarged and heterogeneous pancreas with necrosis of the tail of the pancreas involving the left kidney (fig 2). Endoscopic ultrasonography did not show any

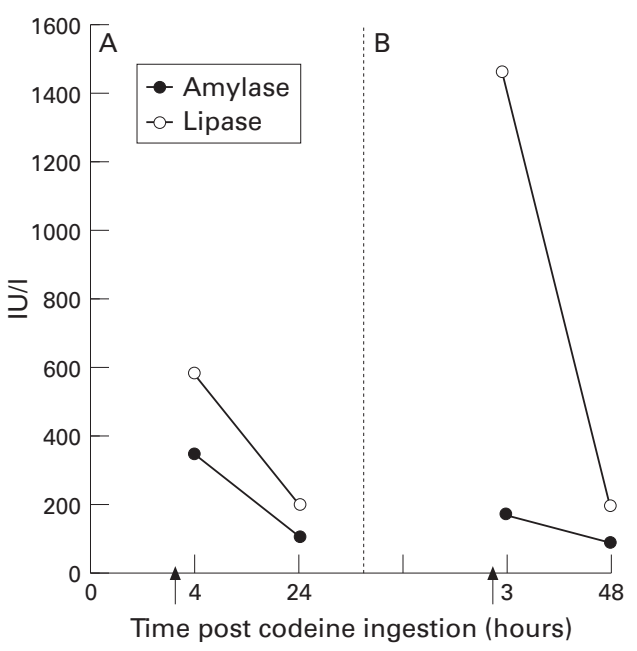

Figure 1: Temporal relation between ingestion of codeine and alterations in serum amylase and lipase during the two episodes ( $A$, first episode; $B$, second episode) of acute pancreatitis.

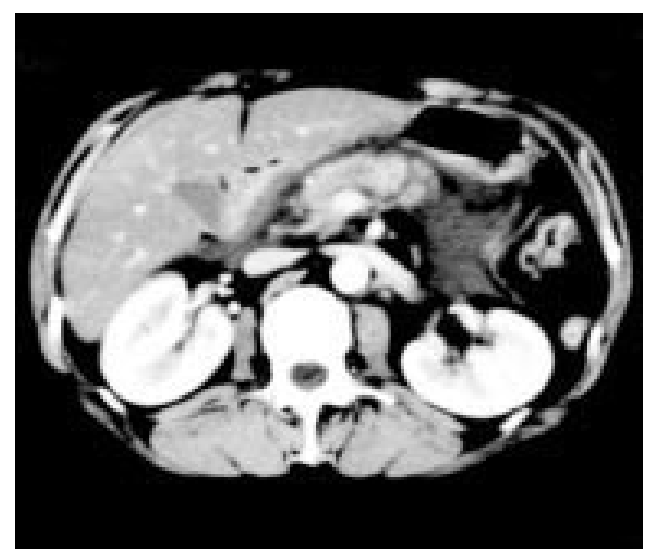

Figure 2: $\quad$ CT scan of abdomen showing an enlarged and heterogeneous pancreas with necrosis of the tail and involvement of the left kidney. 


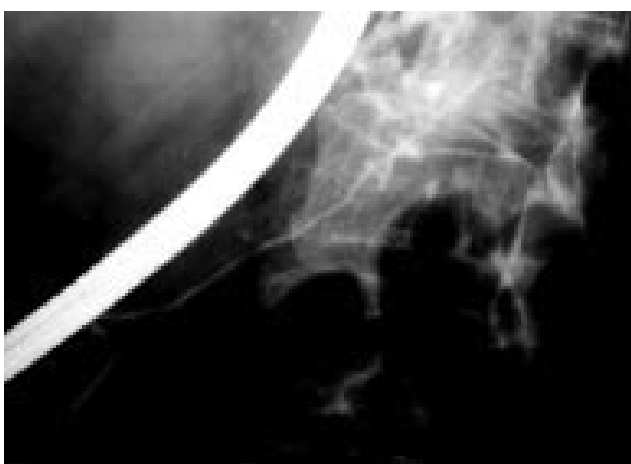

Figure 3: Pancreatogram performed one month after discharge showing a normal pancreatic duct.

evidence of choledocholithiasis, cystic duct lithiasis, or pancreatic calcification. Serum amylase and lipase returned to normal within 48 hours. The patient quickly improved and was discharged seven days later. A CT scan and endoscopic retrograde pancreatography, performed one month later, were normal (fig 3). The patient was advised to abstain from all codeine products. At review, six months later, she was asymptomatic.

\section{Discussion}

This patient had two episodes of acute pancreatitis separated by an interval of one week. On each occasion she had taken $40 \mathrm{mg}$ of codeine three and two hours, respectively, before epigastric pain appeared. She had not taken codeine before and had no history of previous pancreatic pathology. Other causes of acute pancreatitis were excluded, and we believe that codeine was responsible for the patient's condition. It has previously been reported that the majority of cases of drug induced pancreatitis are mild; these two episodes of codeine induced acute pancreatitis settled with conservative treatment. ${ }^{4}$

It has been suggested in experimental studies that codeine ingestion may be associated with pancreatitis. In a study from the Mayo Clinic, $130 \mathrm{mg}$ codeine was injected subcutaneously into 28 subjects. ${ }^{5}$ Pancreatic enzymes increased in seven subjects, beginning two hours after the injection and resolving within one to two days. In one subject, rechallenge resulted in an increase in enzyme concentrations. ${ }^{5}$ Some of these subjects experienced transient epigastric pain after the injection. Acute pancreatitis may occur after the first administration, as in our case, within three or four hours of exposure, and recur within hours of rechallenge, independently of the dose taken.

The pathophysiology probably results from constriction of the sphincter of Oddi. This phenomenon has been demonstrated by subcutaneous injection with therapeutic doses of morphine and codeine (which only differ by methylation of a phenolic hydroxy group). Constriction occurs within five minutes and lasts for at least two hours. ${ }^{6-8}$ Despite these findings, there are no recorded cases of opiate induced sphincter of Oddi spasm resulting in pancreatitis. Because of the reduced reservoir capacity in patients who have had a cholecystectomy, constriction of the sphincter of Oddi may be more likely to have deleterious effects than in normal individuals.

Codeine is a widely used drug, both in over the counter and prescribed preparations. Acute pancreatitis should be considered as a possible side effect of this compound, especially in patients who have had a cholecystectomy.

1 McArthur KE. Drug-induced pancreatitis. Aliment Pharmacol Ther 1996; 10: 23-8.

2 Mallory A, Kern F Jr. Drug-induced pancreatitis: a critical review. Gastroenterology 1980; 78: 813-20.

3 Hastier P, Demarquay JF, Maes B, Caroli-Bosc FX, Chichmanian RM, Dumas R, Delmont JP. Acute pancreatitis induced by codeine-acetaminophen association: a case report with positive rechallenge. Pancreas 1996; 3: 324-6.

4 Lankisch PG, Droge M, Gottesleben F. Drug induced pancreatitis: incidence and severity. Gut 1995; 37: 565-7.

5 Gross JB, Comfort MW, Mathieson DR, Power MH. Elevated values for serum enzymes and lipase following the administration of opiates: a preliminary report. Proc Mayo Clinic 1951; 26: 81-7.

6 Jaffe JH, Martin WR. Opiod analgesics and antagonists. In: Goodman LS, Gilman A, eds. The pharmacological basis of Goodman LS, Gilman A, eds. The pharmacological basis of

7 Steinberg WM, Toskes PP, Salvato RF. Non-specificity of the Morphine-Prostigim Test [abstract]. Gastroenterology 1979; 76: A1255.

8 Roberts-Thompson IC, Toouli J. Abnormal responses to morphine-neostigmine in patients with undefined biliarytype pain. Gut 1985; 26: 1367-7. 